\title{
Trial Methodology in Soft Tissue Sarcomas; the ‘One Plus One is Three or Zero' Phenomenon
}

\author{
Stefan Sleijfer Jaap Verweij \\ Department of Medical Oncology, Erasmus University Medical Centre, location Daniel den Hoed Cancer Centre, Rotterdam, \\ The Netherlands
}

The group of soft tissue sarcomas (STS) is a very heterogeneous group of tumors comprising more than 40 different subtypes. For patients presenting with advanced or metastatic disease, the prognosis is poor with a median overall survival of $10-12$ months. First-line palliative chemotherapy is singleagent doxorubicin [1,2], with ifosfamide as a valid alternative [3]. Several trials explored whether combination chemotherapy yields improved outcomes over doxorubicin alone but until now, there is no proven benefit for multi-drug combinations in terms of prolonged overall survival while such combinations are at the expense of increased toxicity [2]. Currently, there is no established second-line therapy.

Hopefully, this gloomy picture may shortly change due to advances made based on novel insights. One of these is the recognition that the management of STS should be tailored according to the STS subtype. Until recently, all STS subtypes were treated equally. However, STS subtypes largely differ from each other in terms of pathogenesis, clinical behavior, and responses to systemic agents. It is therefore a logical step to explore systemic agents in specific subtypes and the success obtained with imatinib in patients with advanced GIST robustly underlines the correctness of this approach [4]. As a consequence, more and more studies have been and are designed to examine novel compounds in particular STS subtypes. Largely through this approach, new therapies gleam at the horizon for several of those subtypes including taxanes for patients with angiosarcomas of the scalp [5], and trabectedin (ecteinascidin-743) for patients with myxoid liposarcomas [6]. In addition, pazopanib, a tyrosine kinase inhibitor (TKI) directed towards the vascular-endothelial growth factor receptors (VEGFR) and the platelet-derived growth factor receptors (PDGFR), exhibits anti-tumor activity in leiomyosarcomas, synovial sarcomas, and other STS subtypes, but not against adipocytic sarcomas [7]. It should be emphasized, however, while trabectedin has recently been registered by
EMEA, that although all these drugs look promising at first glance, they must be assessed in randomized studies to further explore and refine their activity.

Another novel approach that currently attracts much attention is the pharmacologically based sequential drug combination of gemcitabine and docetaxel. As single agents for the whole group of STS, both drugs are deemed inactive but with respect to specific subtypes, docetaxel is suggested to exhibit activity against angiosarcomas [8] and gemcitabine against uterine leiomyosarcomas and high-grade undifferentiated pleiomorphic sarcomas [9]. In a randomized phase II study, the combination of gemcitabine and docetaxel was compared to single-agent gemcitabine in 122 patients with advanced STS who previously underwent 0-3 lines of chemotherapy [9]. Although this study was not powered to establish differences between both arms and although no differences in the primary endpoint (complete or partial response within 24 weeks, or stable disease lasting longer than 24 weeks) were seen, the gemcitabine-docetaxel combination was suggested to be superior, based on a longer progression-free and overall survival. The number of each of the specific STS subtypes was too small to assess differences between both regimens according to subtype, but it was suggested that gemcitabine-docetaxel was in particular active against uterine leiomyosarcomas and highgrade undifferentiated pleiomorphic sarcomas [9]. Despite the preliminary nature of these data and the severe toxicities [9, 10], this regimen is currently widely applied to treat doxorubicin- and/or ifosfamide refractory patients and is even used as first-line therapy.

In the current issue of ONKOLOGIE, Ebeling et al. [11] report on a single-center experience with this combination in heavily pretreated patients with STS. No complete responses were encountered, partial responses were observed in 5 out of 34 patients. Of the 5 partial responses, 4 patients had a leiomyosarcoma, but so had also the majority of patients (23 out of 34 ).

\begin{tabular}{ll}
\hline KARGER & ( 2008 S. Karger GmbH, Freiburg \\
Fax +497614520714 & Accessible online at: \\
$\begin{array}{l}\text { E-mail Information@Karger.de } \\
\text { www.karger.com }\end{array}$ & www.karger.com/onk
\end{tabular}

Stefan Sleijfer, MD, PhD

Department of Medical Oncology, Erasmus University Medical Centre,

location Daniel den Hoed Cancer Centre

Groene Hilledijk 301, 3075 EA Rotterdam, The Netherlands

Tel. +31 10-4391733, Fax -4391003

E-mail s.sleijfer@erasmusmc.nl 
Median time to progression was 2.4 months, median overall survival 12.5 months and the progression-free rate at 3 months was $38 \%$. Since enhanced activity for this combination was previously suggested in leiomyosarcomas $[9,10]$ and the majority of patients had leiomyosarcomas, the outcomes for this subgroup were separately reported; median time to progression, median overall survival, and the progression-free rate at 3 months for this subgroup was 2.8 months, 17 months, and $45 \%$, respectively. The study confirmed the considerable toxicity of the gemcitabine and docetaxel regimen.

While interesting, the results of this study should be interpreted with caution. Like in many other studies conducted in STS patients, a strong emphasis is put on achieved responses. However, there is accumulating evidence that response rate is not an adequate primary endpoint in studies in advanced STS patients. In a multi-variate analysis of 2,185 patients participating in European Organization of Research and Treatment of Cancer Soft Tissue and Bone Sarcoma Group (EORTCSTBSG) studies [12], a high tumor grade was associated with a better response to chemotherapy but with a shorter overall survival, a phenomenon that was confirmed in other series [13]. This strongly suggests that tumors with a higher proliferation rate are initially more sensitive to chemotherapy, but become resistant to therapy shortly thereafter, which is followed by rapid progression resulting in a short overall survival. In addition, many currently explored therapies such as VEGFRTKIs yield anti-tumor activity which is not clearly reflected in tumor responses. The VEGFR-TKI sorafenib produced a low response rate of only $10 \%$ in patients with renal cell carcinoma, but prolonged the progression-free and overall survival compared to placebo [14]. Likewise, pazopanib, another VEGFR-TKI, induced only a few responses in a phase II study of the EORTC-STBSG, but yielded interesting progression-free and overall survival in several STS subgroups compared to historical data [7]. As a result, response rates should get a less prominent place in studies performed in advanced STS patients. For phase II studies aiming to screen whether or not a certain therapy exhibits activity in STS, the progressionfree rate (PFR) at a certain time point is considered a more relevant end point. To be used in such studies, Van Glabbeke et al. provided PFR at 3 and 6 months associated with active and inactive therapies for both first and second line in advanced STS [15] based on a large EORTC-STBSG data-set. Another comment that has to be made concerns the usefulness of studies as the study by Ebeling et al. First of all, the study was retrospective in nature and such series are highly prone to selection bias as can already be denoted from the exceptionally high number of patients with leiomyosarcomas in the study. Furthermore, if a combination of drugs is explored, a combination that includes at least one active drug as holds true for gemcitabine-docetaxel, may yield activity based on the activity of either agent. However, whether such a combination is superior compared to the respective single agents or any other therapy remains unknown. It is therefore strongly recommended to perform phase II-like studies with combinations only in the context of a randomized design [16], as was actually done in the randomized phase II study [9]. If the experimental arm is considered promising, the study can be extended into a phase III trial thereby decreasing the risk to expose patients to a potential suboptimal therapy, while money and time is saved. There is now enough evidence that the gemcitabine-docetaxel yields anti-tumor activity in STS. However, this is based on a non-randomized phase II study [10], retrospective series, and on one randomized phase II study [9] that was not powered to adequately assess survival differences. There is thus an urgent need to perform randomized phase III studies including the gemcitabine-docetaxel combination as one of the experimental arms with appropriate stratification for histologic STS subtypes. Only such a study can tell us whether or not gemcitabine-docetaxel deserves a place in the management of advanced STS patients. Of course the execution of studies in STS is hindered by the rare occurrence of STS, but the story of imatinib in GIST has convincingly shown that such problems can be overcome through intensive international collaboration offered by platforms such as the EORTC and CONTICANET.

\section{Acknowledgement}

This work was supported by the EC FP6 CONTICANET project (LSHCCT-2005-018806) from the European Commission.

\section{References}

1 Sleijfer S, Seynaeve C, Verweij J: Using single-agent therapy in adult patients with advanced soft tissue sarcoma can still be considered standard care. Oncologist 2005;10:833-841.

2 Bramwell VHC, Anderson D, Charette ML: Doxorubicin-based chemotherapy for the palliative treatment of adults with locally advanced or metastatic soft tissue sarcoma. The Cochcrane Database of systematic reviews 2001; issue 4. Most recent amendment 27 july 2001 .
3 Tascilar M, Loos WJ, Seynaeve C, Verweij J, Sleijfer $\mathrm{S}$ : The pharmacalogic base ifosfamide use in adult patients with advamnced soft tissue sarcomas. The Oncologist 2007;12:1351-1360.

4 Verweij J, Casali PG, Zalcberg J, LeCesne A, Reichhardt P, Blay JY, Issels R, Van Oosterom A, Hogendoorn P, Van Glabbeke M, Bertulli R, Judson I: Progression-free survival in gastrointestinal stromal tumours with high-dose imatinib: a randomised trial. Lancet 2004;364:1127-1134. $\checkmark 5$ Fata F, O'Reilly E, Illson F, Pfister D, Leffel D, Kelsen DP, Schwartz GK, Casper ES: Paclitaxel in the treatment of patients with angiosarcoma of the scalp or face. Cancer 1999;86:2034-2037.

6 Grosso F, Jones RL, Demetri G, Judson I, Blay JY, LeCesne A, Sanfillipo R, Casierie P, Collini Dileo P, Spreafico C, Stachiotti S, Tamborini E, Tercero JC, Jimino J, D'Incalci M, Gronchi A, Fletcher JA, Pilotti S, Casali PG: Efficacy of trabectedin (ecteinascidin-743) in advanced pretreated myxoid liposarcomas: a retrospective study. Lancet Oncol 2007;8:595-602. 
7 Sleijfer S, Ray-Coquard I, Papai Z, Le Cesne A, Scurr M, Schöffski P, Collin F, Pandite L, Marraeaud S, De brauwer A, Blay JY: Pazopanib (GW786034) in patients (pts) with relapsed or refractory soft tissue sarcoma (STS); a phase II study from the EORTC STBSG (EORTC 62043). Annual Meeting Connective Tissue Oncol Soc 2007, abstr 875.

8 Isogai R, Kawada A, Aragana Y, Tezuka T: Successful treatment of pulmonary metastasis and local recurrence of angiosarcoma with docetaxel. J Dermatol 2004;31:335-341

9 Maki R, Watjhen JK, Patel SR, Priebat DA, Okuno SH, Samulas B, Fanucchi M, Harmon DC, Schuetze SD, Reinke D, Thall PF, Benajmin RS, Baker LH, Hensley ML: Randomized phase II study of gemcitabine and docetaxel compared with gemcitabine alone in patients with metastatic soft tissue sarcomas: results of sarcoma alliance for research through collaboration study 002. J Clin Oncol 2007; 25:2755-2763.
10 Hensley ML, Maki R, Venkatraman E, Geller G, Lovegren M, Aghajanian C, Sabatinni P, Tong W, Barakat R, Spriggs DR: Gemcitabine and docetaxel in patients with unresectable leiomyosarcoma: results of a phase II trial. J Clin Oncol 2002;20: 2824-2831.

11 Ebeling P, Eisele L, Schuett P, Bauer S, Schuette J, Moritz T, Seeber S, Flasshove M: Docetaxel and gemcitabine in the treatment of soft tissue sarcoma - a single-center experience. Onkologie 2008;31: DOI: $10.1159 / 000111756$.

12 Van Glabbeke M, Van Oosterom AT, Oosterhuis JW, Mouridsen H, Crowther D, Somers R, Verweij J, Santoro A, Buesa J, Tursz T: Prognostic factors for the outcome of chemotherapy in advanced soft tissue sarcoma: an analysis of 2,185 patients treated with anthracycline-containing first-line regimens- A European Organization of Research and Treatment of Cancer Soft Tissue and Bone Sarcoma Group. J Clin Oncol 1999;17:150-167.
13 Antman K, Crowley J, Balcerzak SP, Rivkin SE, Weis GR, Elias A, Natale RB, Cooper RM, Barlogie B, Trump DL: An intergroup phase III randomized study of doxorubicin and dacarbazine with or without ifosfamide and mesna in advanced soft tissue and bone sarcomas. J Clin Oncol 1993;11: 1276-1285.

14 Escudier B, Eisen T, Stadler WM, Scszylik C, Oudard S, Siebels M, Negrier S, Chevreau C, Solska E, Desai AA, Rolland F, Demkow T, Hutson TE, Gore M, Freeman S, Schwartz B, Shan M, Simantov R, Bukowski RM: Sorafenib in advanced clear-cell renal cell carcinoma. New Engl J Med 2007;356: 125-134.

15 Van Glabbeke M, Verweij J, Judson I, Nielsen OS: Progression-free rate as the principal end-point for phase II trials in soft-tissue sarcomas Eur J Cancer 2002;38:543-549.

16 Van Glabbeke M, Steward W, Armand JP: Nonrandomised phase II trials of drug combinations: often meaningless, sometimes misleading. Are there alternative strategies? Eur J Cancer 2002;38: $635-638$. 